University of Wollongong

Research Online

Australian Institute for Innovative Materials -

Papers

Australian Institute for Innovative Materials

$1-1-2014$

\title{
A novel carbon nanotube modified scaffold as an efficient biocathode material for improved microbial electrosynthesis
}

Ludovic Jourdin

University of Queensland

Stefano Freguia

University of Queensland

Bogdan C. Donose

University of Queensland

Jun Chen

University of Wollongong, junc@uow.edu.au

Gordon G. Wallace

University of Wollongong, gwallace@uow.edu.au

See next page for additional authors

Follow this and additional works at: https://ro.uow.edu.au/aiimpapers

Part of the Engineering Commons, and the Physical Sciences and Mathematics Commons

Research Online is the open access institutional repository for the University of Wollongong. For further information contact the UOW Library: research-pubs@uow.edu.au 


\title{
A novel carbon nanotube modified scaffold as an efficient biocathode material for improved microbial electrosynthesis
}

\begin{abstract}
We report on a novel biocompatible, highly conductive three-dimensional cathode manufactured by direct growth of flexible multiwalled carbon nanotubes on reticulated vitreous carbon (NanoWeb-RVC) for the improvement of microbial bioelectrosynthesis (MES). NanoWeb-RVC allows for an enhanced bacterial attachment and biofilm development within its hierarchical porous structure. 1.7 and 2.6 fold higher current density and acetate bioproduction rate normalized to total surface area were reached on NanoWeb-RVC versus a carbon plate control for the microbial reduction of carbon dioxide by mixed cultures. This is the first study showing better intrinsic efficiency as biocathode material of a threedimensional electrode versus a flat electrode: this comparison has been made considering the total surface area of the porous electrode, and not just the projected surface area. Therefore, the improved performance is attributed to the nanostructure of the electrode and not to an increase in surface area. Unmodified reticulated vitreous carbon electrodes lacking the nanostructure were found unsuitable for MES, with no biofilm development and no acetate production detected. The high surface area to volume ratio of the macroporous RVC maximizes the available biofilm area while ensuring effective mass transfer to and from the biofilm. The nanostructure enhances the bacteria-electrode interaction and microbial extracellular electron transfer. When normalized to projected surface area, current densities and acetate production rates of $3.7 \mathrm{~mA} \mathrm{~cm}-2$ and $1.3 \mathrm{mM} \mathrm{cm}-2 \mathrm{~d}-1$, respectively, were reached, making the NanoWeb$\mathrm{RVC}$ an extremely efficient material from an engineering perspective as well. These values are the highest reported for any MES system to date.
\end{abstract}

\section{Keywords}

carbon, nanotube, modified, scaffold, efficient, biocathode, material, improved, microbial, novel, electrosynthesis

\section{Disciplines}

Engineering | Physical Sciences and Mathematics

\section{Publication Details}

Jourdin, L., Freguia, S., Donose, B. C., Chen, J., Wallace, G. G., Keller, J. \& Flexer, V. (2014). A novel carbon nanotube modified scaffold as an efficient biocathode material for improved microbial electrosynthesis. Journal of Materials Chemistry A, 2 (32), 13093-13102.

\section{Authors}

Ludovic Jourdin, Stefano Freguia, Bogdan C. Donose, Jun Chen, Gordon G. Wallace, Jurg Keller, and Victoria Flexer 


\title{
A novel carbon nanotube modified scaffold as an efficient biocathode material for improved microbial electrosynthesis
}

\author{
Ludovic Jourdin $^{\text {*a,b }}$, Stefano Freguia ${ }^{\mathrm{a}, \mathrm{b}}$, Bogdan C. Donose ${ }^{\mathrm{a}, \mathrm{b}}$, Jun Chen ${ }^{\mathrm{c}}$, Gordon \\ G. Wallace ${ }^{\mathrm{c}}$, Jurg Keller ${ }^{\mathrm{a}}$, and Victoria Flexer $^{{ }^{a}, \neq}$
}

\begin{abstract}
We report on a novel biocompatible, highly conductive three-dimensional cathode manufactured by direct growth of flexible multiwalled carbon nanotubes on reticulated vitreous carbon (NanoWeb-RVC) for the improvement of microbial bioelectrosynthesis (MES). NanoWeb-RVC allows for an enhanced bacterial attachment and biofilm development within its hierarchical porous structure. 1.7 and 2.6 fold higher current density and acetate bioproduction rate normalized to total surface area were reached on NanoWebRVC versus a carbon plate control for the microbial reduction of carbon dioxide by mixed cultures. This is the first study showing better intrinsic efficiency as biocathode material of a three-dimensional electrode versus a flat electrode: this comparison has been made considering the total surface area of the porous electrode, and not just the projected surface area. Therefore, the improved performance is attributed to the nanostructure of the electrode and not to an increase in surface area. Unmodified reticulated vitreous carbon electrodes lacking the nanostructure were found unsuitable for MES, with no biofilm development and no acetate production detected. The high surface area to volume ratio of the macroporous RVC maximizes the available biofilm area while ensuring effective mass transfer to and from the biofilm. The nanostructure enhances the bacteria-electrode interaction and microbial extracellular electron transfer. When normalized to projected surface area, current densities and acetate production rates of $3.7 \mathrm{~mA} \mathrm{~cm} \mathrm{~cm}^{-2}$ and $1.3 \mathrm{mM} \mathrm{cm}^{-2}$ day $^{-1}$, respectively, were reached, making the NanoWeb-RVC an extremely efficient material from an engineering perspective as well. These values are the highest reported for any MES system to date.
\end{abstract}

\section{Introduction}

Bioelectrochemical systems (BESs) are emerging bioreactor technologies that have substantially expanded their scope over the last few years, from electricity generation (microbial fuel cells, MFCs) to an array of more complex processes, such as bioremediation and chemical production. ${ }^{1,2}$ The threat of global warming and diminishing fossil fuel resources, which our society heavily depends on, is creating a rapidly growing demand for new technologies for the renewable production of fuels and chemicals. Microbial electrosynthesis (MES) is a novel and promising strategy that relies on electroactive microorganisms that are able to use electrons derived from solid-state electrodes to catalyse the reduction of carbon dioxide and other oxidised organics, to generate extracellular multi-carbon organic molecules as valuable reduced endproducts. $^{2-4}$ In this perspective, MES might also be considered as an interesting option to capture and increase the value of the electrical energy produced from intermittent renewable sources such as solar and wind. ${ }^{5}$ Moreover, $\mathrm{CO}_{2}$-based bioproduction presents several advantages such as independence of arable land and precious freshwater resources, limited toxicity to microorganisms, and most importantly, nearly unlimited substrate availability, as $\mathrm{CO}_{2}$ can be removed from the atmosphere, or captured before its release (waste gas, e.g. from power production) to minimise increase in the atmospheric concentration. ${ }^{6} \mathrm{CO}_{2}$ can also be found in excess in seawater and in solid minerals.

Nevin et al. ${ }^{7,} 8$ described the first proof of concept of a biocathode-driven $\mathrm{CO}_{2}$ reduction to acetate using pure cultures of acetogenic bacteria. Subsequent studies by Marshall et al. demonstrated the ability of mixed cultures to perform electroacetogenesis, with improved production rates over longterm operation ${ }^{9,}{ }^{10}$. Use of mixed microbial consortia is attractive as they are readily obtainable in large quantities and are more tolerant to environmental stress and fluctuation ${ }^{11}$. 
However, pure cultures could lead towards higher product specificity. To date, only acetogenic microorganisms have demonstrated the ability to reduce carbon dioxide to multicarbon organic compounds, using electricity as the sole energy source. Even though acetate can be an important end-product or platform for further chemical synthesis, modification of microbial pathways of known electroactive microorganisms capable of MES, such as Clostridium ljungdahilii, has been proposed in order to increase production rates and redirect both carbon and electron fluxes towards the production of more valuable chemicals ${ }^{3,12,13}$.

Optimizing and scaling microbial electrosynthesis to practical applications relies on performance improvements while maintaining low costs. Enhancement of bacterial attachment, biofilm development, electron transfer rate at the cathode surface (microorganism-electrode interaction), and chemical production rate will require optimization of several key elements, particularly improved cathode materials, selective microbial consortia and efficient reactor designs. Moreover, the electrode material must be scalable, highly conductive and cost effective.

Until very recently, research on prospective electrode materials for BES and biosensors was only focused on the anodic processes. Several approaches have been reported. Improved biofilm attachment and biofilm activity (by increasing the rate of electron transfer) were achieved by modifying the electrode surface, either by establishing a positively-charged surface via a number of surface treatments ${ }^{14-18}$ or by fixing redox molecules ${ }^{19-22}$. Reduction of the activation energy threshold for electron transfer from electrodes to microorganisms was shown by applying metal catalysts ${ }^{23-26}$. Finally, increasing the available surface area for biofilm growth by using rough or porous materials is a well-proven strategy ${ }^{27-32}$.

Despite the large number of reports on new electrode materials and surface modification strategies for the improvement of anodic processes, there is hardly any work reported on new electrodes materials for cathodes. This is not surprising, since there is now quite a general agreement that bacteria-electrode electron transfer processes are most probably following different routes during an anodic or cathodic process. ${ }^{2,} 4$ Therefore, it is not straightforward to predict that a given electrode material yielding good results as a microbial anode will perform equally well as a cathode.

To the best of our knowledge, only Lovley et al. ${ }^{33,34}$ have very recently proposed a number of modified electrode materials for the improvement of cathodic processes. Their work focuses on the improvement of microbial electrosynthesis of acetate from $\mathrm{CO}_{2}$ by pure cultures of Sporomusa ovata. Using different treatments, they altered the surface chemistry of carbon cloth by the immobilization of positively charged molecules, and reported increases in both current density and acetate production rate, compared to untreated carbon cloth. ${ }^{33}$ The best results were obtained by cathode functionalization with chitosan and cyanuric chloride, with 6-7 fold higher production rates (ca. $0.02 \mathrm{mM} \mathrm{day}^{-1} \mathrm{~cm}^{-2}$ ) and highest current density of $0.0475 \mathrm{~mA} \mathrm{~cm}^{-2}$ reached with a chitosan modified electrode.
However, not all surface treatments increasing the positive charge were found to be successful, suggesting that surface charge alone might not be sufficient.

It can be predicted that transfer of substrate and products to and from the electrode surface, can limit the current density of biocathodes and production rate for microbial electrosynthesis at flat and rough electrodes, in a similar fashion as it has already been described for anodic biofilms ${ }^{35}$, 36 . Threedimensional cathodes with macropores at least in the hundreds of micrometer scale in all three geometric directions could overcome those limitations and allow for efficient mass transfer towards and from the electroactive biofilm ${ }^{28}$. We refer here to porous three-dimensional materials, where microorganisms can develop in the whole volume of the electrode, as opposed to rough or dense fibrous materials. For example, on graphite felt a biofilm is only developed in the outer layers of the fibre mat, but not 2-3mm from the surface in the deepest core of the electrode. Moreover, a high surface-to-volume ratio, as is typical for three-dimensional electrodes, will provide a large surface area and therefore increase the active biomass and the maximum current consumption per given volume unit. Reticulated vitreous carbon (RVC) is a rather cheap and commercially available open-pore foam material of honeycomb structure used in a few microbial fuel cell studies ${ }^{28-31}$. RVC has a number of advantages for bioelectrochemical systems and MES in particular, such as a very high surface area to volume ratio, high electrical conductivity, strong chemical and heat resistance and minimal reactivity over a wide range of conditions $^{37}$. However, they have also been found not to have the most favourable surface characteristics for microbial attachment and electron transfer ${ }^{28}$.

Carbon nanotube-based (CNT) electrode materials have become extremely attractive for application in BES. Indeed, CNTs have large aspect ratios, high surface area, and an exceptional electric conductivity along their length ${ }^{38}$. Moreover, their mechanical strength and chemical stability are excellent. CNTs were also described as being highly biocompatible allowing for bacteria immobilization and proliferation $^{28,39}$. So far, most studies were carried out in MFC configuration; electrodes were coated with CNT inks and produced promising current densities ${ }^{15}$, 40-43. CNT ink deposition on cotton and polyester fabrics also yielded biocathodes with up to 3 times higher current density (0.021 $\left.\mathrm{mA} \mathrm{cm}^{-2}\right)$ and acetate microbial electrosynthesis rates $(0.010$ $\mathrm{mM}$ day $^{-1} \mathrm{~cm}^{-2}$ ) than carbon cloth controls ${ }^{33}$.

To enable a good connection of the CNT to the substrate, a new CNT growth technique has been developed, which achieves CNT development directly on any type of surface, including conductive substrates ${ }^{44}$. This approach was used to synthesize a new biocompatible, highly conductive threedimensional microbial bioelectrode, with a hierarchical porous structure, by direct growth of multiwalled carbon nanotubes on reticulated vitreous carbon, called NanoWeb-RVC ${ }^{28}$. The NanoWeb-RVC showed excellent performance as bioanode material for power production, with one of the highest current density of $6.8 \mathrm{~mA} \mathrm{~cm}^{-2}$ ever recorded ${ }^{28}$. This electrode structure 
benefits from all the advantages of both RVC and CNT mentioned above. The macrostructure enhances the mass transfer to and from the electrode surface while the nanostructure improves bacterial attachment to the electrode and increases the extracellular electron transfer rate from the microorganisms to the electrode. To the best of our knowledge, only Schröder et al. ${ }^{27}$ reported a higher current density, using a layered corrugated carbon microbial electrode, with $7 \mathrm{~mA} \mathrm{~cm}{ }^{-2}$ for their basic electrode configuration, and up to $40 \mathrm{~mA} \mathrm{~cm}{ }^{-2}$ when several electrodes were stacked together.

Here we report on the performance of this new microbial electrode material, NanoWeb-RVC, as a biocathode for microbial electrosynthesis of acetate from carbon dioxide with mixed cultures. Results show that NanoWeb-RVC achieves enhanced bacteria attachment and proliferation within its porous structure. The combined effect of both the macrostructure and the nanostructure of NanoWeb-RVC can effectively enhance current consumption and microbial electrosynthesis rates.

\section{Results and discussion}

Starting right after inoculation, current consumption at a fixed cathode potential of $-0.85 \mathrm{~V}$ vs. SHE was recorded during 140 days for three electrodes (each in duplicate): a graphite plate (as control), unmodified RVC and NanoWeb-RVC. During this period, carbon dioxide consumption as well as volatile fatty acids production was followed for each reactor. Results for the three different types of electrodes were compared to assess efficiency. All data points in Fig. 1 and Fig. 2 have been normalized to the total surface area of the electrodes. Reported values in the text have also been normalized to total surface area unless otherwise specified. Values normalized to both projected and total surface area are presented in Table 1 and 2 . It is important to understand the difference between these two ways of normalizing the current density.

The projected surface area refers to the footprint of the electrode (the area of the base of the electrode, irrespectively whether it is a $3 \mathrm{D}$ or a flat electrode). The total surface area refers to the area within the RVC scaffold before NanoWeb deposition. This means we are considering the total surface area available for bacteria immobilization, i.e. including the surface area of the macropores within the scaffold. The value of the total area is indeed much higher than the projected surface area of the electrode. For a 45 ppi RVC scaffold, a value of 26.2 $\mathrm{cm}^{2} \cdot \mathrm{cm}^{-3}$ is given by the RVC manufacturer using the multipoint BET method by the adsorption of Krypton gas at cryogenic temperatures and is confirmed by Friedrich et al. ${ }^{37}$ It is important to notice that we refer here to the total surface area as the total surface area available for microorganisms' immobilization. As reported previously ${ }^{28,44}$, as well as in this work, the pores created within the carbon nanotube web are 100 $\mathrm{nm}$ or smaller (see Fig 3B), i.e. they are at least one order of magnitude smaller than typical bacterial sizes (about $1 \mu \mathrm{m}$ length, see Fig 3F). Therefore, the CNT NanoWeb does not create more available surface area for bacterial immobilization.

\section{Current density enhancement}

The cumulative electron consumption curves during chronoamperometry at constant applied potential of $-0.85 \mathrm{~V}$ are shown in Fig. 1. In all cases, the average of the two duplicate electrodes is plotted. Results of duplicates were in very good agreement and the standard deviation minimal.

Fig. 1. Cumulative electron consumption over time on graphite plate

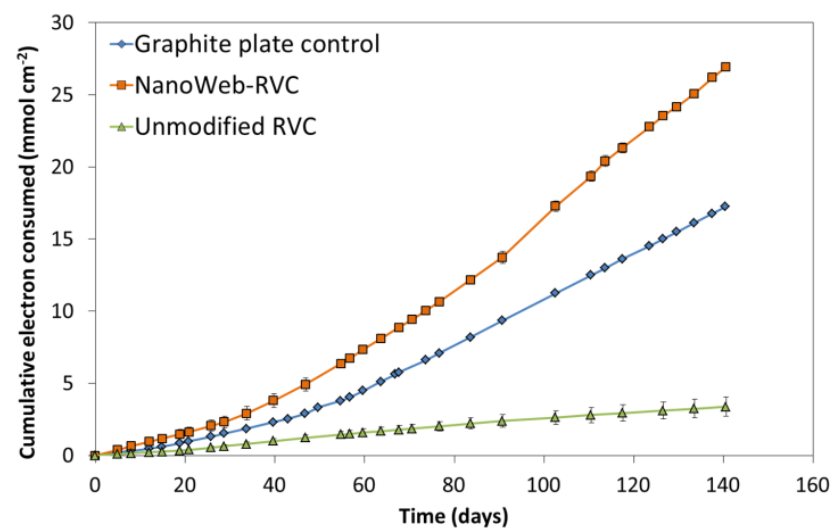

(red square), NanoWeb-RVC (blue diamond) and unmodified RVC (green triangle), normalized to the total surface area.

The electron consumption rate is defined as the slope of those curves at different time intervals. Table 1 summarizes the maximum electron consumption rate and the maximum current density values reached on each electrode. On graphite plate, the electrons were consumed at a slower rate within the first 33 days. Then, the electron consumption rate increased up to maximum rate of $0.157 \mathrm{mmol} \mathrm{cm}^{-2}$ day $^{-1}$ over the last 85 days of the test. Three phases were observed on NanoWeb-RVC. A first lag period of 33 days, followed by a 2.3-fold rate increase with the consumption of $0.19 \mathrm{mmol} \mathrm{cm}^{-2}$ day $^{-1}$ of electrons from day 33 to 91 . Finally, from day 91 to the end of the test, $0.260 \mathrm{mmol} \mathrm{cm}^{-2}$ electrons were consumed, corresponding to a cathodic current density of $0.291 \mathrm{~mA} \mathrm{~cm}{ }^{-2}$. Conversely, a constant current throughout the 140 days of the experiment was recorded on unmodified RVC electrodes, with an electron consumption rate of $0.025 \mathrm{mmol} \mathrm{cm}^{-2} \mathrm{day}^{-1}$.

Table 1 Maximum electron consumption rates and corresponding current densities reached on the three types of electrodes normalized both to the projected and total surface area. Values shown were averaged from day 55 to 140 for graphite plates, from day 91 to 140 for NanoWeb-RVC and over the whole 140 days period for unmodified RVC.

\begin{tabular}{|c|c|c|c|c|}
\hline & \multicolumn{2}{|c|}{$\begin{array}{c}\text { Electron consumption rate } \\
\left(\mathrm{mmol} \mathrm{e}-\mathrm{cm}^{-2} \text { day }^{-1}\right)\end{array}$} & \multicolumn{2}{|c|}{$\begin{array}{c}\text { Current density } \\
\left(\mathrm{mA} \mathrm{cm} \mathrm{cm}^{-2}\right)\end{array}$} \\
\hline & $\begin{array}{c}\text { vs. projected } \\
\text { area }\end{array}$ & $\begin{array}{l}\text { vs. total } \\
\text { area }\end{array}$ & $\begin{array}{l}\text { vs. Projected } \\
\text { area }\end{array}$ & vs. total area \\
\hline $\begin{array}{c}\text { Graphite plate } \\
\text { control } \\
\end{array}$ & $0.157 \pm 0.001$ & $\begin{array}{c}0.157 \pm \\
0.001 \\
\end{array}$ & $0.176 \pm 0.001$ & $\begin{array}{c}0.176 \pm \\
0.001 \\
\end{array}$ \\
\hline $\begin{array}{c}\text { Unmodified } \\
\text { RVC } \\
\end{array}$ & $0.32 \pm 0.07$ & $\begin{array}{c}0.025 \pm \\
0.004\end{array}$ & $0.37 \pm 0.08$ & $\begin{array}{c}0.028 \pm \\
0.004\end{array}$ \\
\hline $\begin{array}{l}\text { NanoWeb- } \\
\text { RVC }\end{array}$ & $3.3 \pm 0.3$ & $\begin{array}{c}0.260 \pm \\
0.004\end{array}$ & $3.7 \pm 0.3$ & $\begin{array}{c}0.291 \pm \\
0.004\end{array}$ \\
\hline
\end{tabular}

Remarkably, the electron consumption rate (and hence the current density) on NanoWeb-RVC was higher than on graphite plate for the whole duration of the experiment, and reached 
values 65\% higher over the last 50 days of the experiment. To the best of our knowledge, this is the first study reporting a higher current density normalized by total surface area for a porous three-dimensional electrode compared to a rough electrode.

Most literature reports on novel porous electrodes for bioelectrochemical systems report current values normalized to the projected surface area of the electrodes ${ }^{28,30,33,40,43}$. While these reports are certainly justified from an engineering perspective, they do not provide relevant information on the intrinsic efficiency of the electrode material. Indeed, for many reports on new materials, if the total current would be normalized to the total available surface area, these materials would lag behind when compared to conventional rough electrodes, such as carbon cloth or plates ${ }^{28,30,33,40}$. With the exception of a few examples ${ }^{27}$, the main reason for this failure is the lack of adequate porosity to guarantee efficient mass transport to and from the electrode surface.

Normalizing the NanoWeb-RVC performance by projected surface area results in a very high cathodic current density of $3.7 \mathrm{~mA} \mathrm{~cm}{ }^{-2}$. This current is 21 times higher than that measured for a rough graphite plate electrode, hence the NanoWeb-RVC is also an extremely efficient material from this perspective. Most strikingly, as far as we can ascertain, this value represents the highest current density for cathodic microbial $\mathrm{CO}_{2}$ reduction and, in general, the highest cathodic current density ever reported. Min et al. ${ }^{45}$, who studied MES of acetate from $\mathrm{CO}_{2}$ in very similar experimental conditions to ours, reported about 1.8 $\mathrm{mA} \mathrm{cm} \mathrm{cm}^{-2}$ (vs. projected area) consumed at $-0.9 \mathrm{~V}$ by a mixed culture on carbon felt. Rates of electron transfer from stainless steel cathodes to biofilms of Geobacter sulfurreducens consuming up to $2 \mathrm{~mA} \mathrm{~cm}{ }^{-2}$ when reducing fumarate at higher applied potential $(-0.4 \mathrm{~V})$ were previously reported ${ }^{46}$.

Even though a two times greater current density per projected surface area was observed on the unmodified RVC electrode compared to the rough graphite plate, this current corresponds to a 6 times lower electron consumption rate per total surface area. We will analyse the unmodified RVC case after the full experimental evidence has been presented, since in this case the current consumption seems to be associated with a different process.

For the novel NanoWeb-RVC, the combined effect of both the macrostructure and the nanostructure is believed to be the reason for such a high cathodic current density. Indeed, other CNT-based cathodes were not as efficient for microbial electrosynthesis of acetate. Zhang et al. ${ }^{33}$ obtained 0.022 and $0.021 \mathrm{~mA} \mathrm{~cm}^{-2}$ (projected surface area) with their CNT-cotton and CNT-polyester electrode versus $3.7 \mathrm{~mA} \mathrm{~cm}^{-2}$ obtained in this study. Evidently, even though both electrodes in that report and those described here comprise CNTs, they are inherently different in nature. Electrodes reported by Zhang et al. were prepared by dipping non-conductive substrates in a CNT ink. NanoWeb-RVC was synthetized by directly growing CNT on top of a highly conductive substrate, which will guarantee both the high conductivity of the electrodes as well as the homogeneous distribution of CNT on the electrode surface.
Moreover, the experimental conditions in the previous work were different as the authors used a pure culture of Sporomusa ovata and a higher cathode applied potential of $-0.5 \mathrm{~V}$.

\section{Microbial electrosynthesis - $\mathrm{CO}_{2}$ consumption and acetate production rate enhancement}

The carbon dioxide consumption and volatile fatty acids production were followed throughout the experiments and are shown in Fig. 2.

The maximum rates can be seen in Table 2. The main product generated was acetate and no other volatile fatty acids or alcohols accumulated in any of the reactors, in agreement with other mixed culture microbial studies ${ }^{9,10}$. We can observe that both $\mathrm{CO}_{2}$ consumption and acetate production rates were much greater on the NanoWeb-RVC electrode than on the rough graphite electrode.

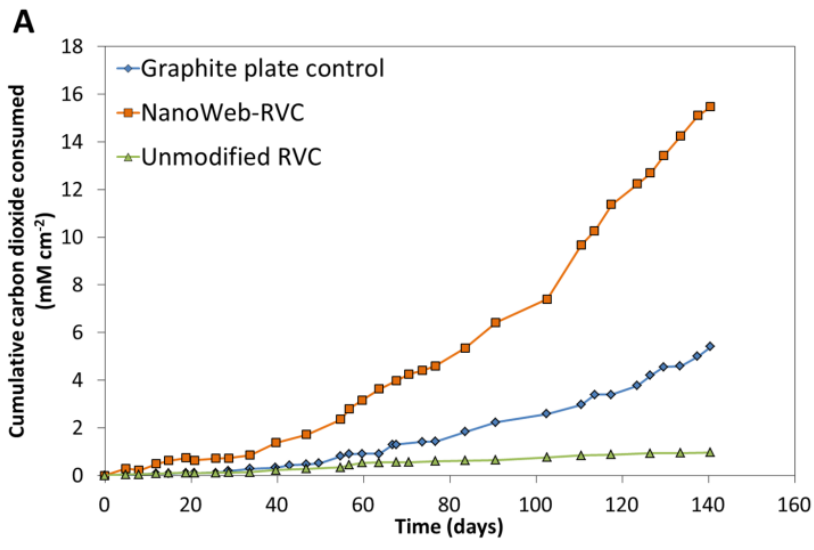

B

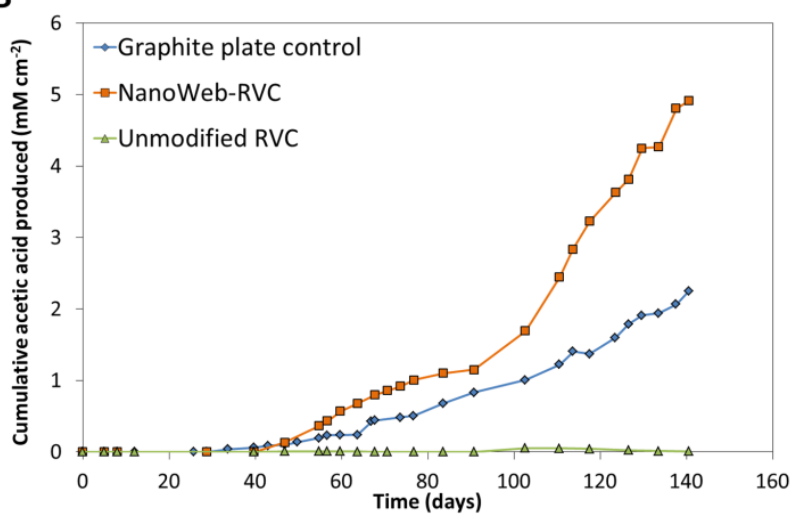

Fig. 2 Carbon dioxide consumption (A) and acetate production (B) over time on graphite plate, NanoWeb-RVC, and unmodified RVC normalized by the total surface area.

Consistent with the electron consumption development shown in Fig. 1, similar phases with increasing rates are observed on both graphite and NanoWeb-RVC electrodes. Lag phases of about 30 and 40 days, respectively, were observed with only a small amount of carbon dioxide consumed by the microbial cultures $\left(0.005\right.$ and $0.028 \mathrm{mM} \mathrm{cm}{ }^{-2}$ day $^{-1}$, for carbon plate and NanoWeb-RVC respectively) and no acetate generation. These lag phases can be explained by the very small amount of sludge inoculated (60 $\mathrm{mg}_{\mathrm{COD}} \mathrm{L}^{-1}$, or $15 \mathrm{mg}_{\mathrm{COD}}$ in the cathode 
compartment). Quite linear trends were then observed on graphite plate electrodes, with maximum $\mathrm{CO}_{2}$ consumption and acetate production rates of 0.078 and $0.039 \mathrm{mM} \mathrm{cm}^{-2} \mathrm{day}^{-1}$. On NanoWeb-RVC electrodes, a first increase was observed up to day 102 followed by a further rate enhancement until the end of the experiment. During this final period, maximum $\mathrm{CO}_{2}$ consumption $\left(0.210 \mathrm{mM} \mathrm{cm}{ }^{-2}\right.$ day $\left.^{-1}\right)$ and acetate production $\left(0.10 \mathrm{mM} \mathrm{cm}^{-2}\right.$ day $\left.^{-1}\right)$ rates were measured, which are 2.7 and 2.6 times greater than measured for the graphite electrode. It was calculated that, within the last phase of the experiments, $88 \pm 16 \%$ and $77 \pm 10 \%$ of the total inorganic carbon consumed was transformed into acetate in the graphite plate and NanoWeb-RVC reactors, respectively. It is assumed that the remaining inorganic carbon was assimilated into biomass. Similarly, $44 \pm 22 \%$ and $70 \pm 11 \%$ of the electrons consumed were recovered in acetate in the graphite plate and NanoWebRVC reactors respectively.

Remarkably, neither acetate nor any other organics were detected throughout the 140 days of operation in the unmodified RVC reactor. This is an indication of the significant importance of the nanostructure of the electrode material to achieve microbial electrosynthesis. Therefore, even though no apparent hydrogen was detected in the reactor, it is believed that most of the electrons consumed on the unmodified RVC were used for proton reduction to hydrogen and the (very small) amount produced may have diffused out of the reactor through the membrane and/or rubber stoppers and tubing. Similar diffusion losses have been reported previously ${ }^{47-51}$.

Table 2 Maximum $\mathrm{CO}_{2}$ consumption and acetate production rates reached on the three types of electrode (averaged from day 102 to 140), normalized both by the projected and total surface area.

\begin{tabular}{|c|c|c|c|c|}
\hline & \multicolumn{2}{|c|}{$\begin{array}{l}\mathrm{CO}_{2} \text { consumption rate } \\
\left(\mathrm{mM} \mathrm{cm} \mathrm{cm}^{-2} \text { day }^{-1}\right)\end{array}$} & \multicolumn{2}{|c|}{$\begin{array}{l}\text { Acetic acid production rate } \\
\left(\mathrm{mM} \mathrm{cm}^{-2} \text { day }^{-1}\right)\end{array}$} \\
\hline & $\begin{array}{l}\text { vs. Projected } \\
\text { area }\end{array}$ & vs. total area & $\begin{array}{l}\text { vs. Projected } \\
\text { area }\end{array}$ & vs. total area \\
\hline $\begin{array}{l}\text { Graphite plate } \\
\text { control }\end{array}$ & $\begin{array}{c}0.078 \pm \\
0.007\end{array}$ & $\begin{array}{c}0.078 \pm \\
0.007\end{array}$ & $\begin{array}{c}0.039 \pm \\
0.009\end{array}$ & $0.039 \pm 0.009$ \\
\hline $\begin{array}{c}\text { Unmodified } \\
\text { RVC }\end{array}$ & $\begin{array}{c}0.070 \pm \\
0.007\end{array}$ & $\begin{array}{c}0.005 \pm \\
0.001\end{array}$ & 0 & 0 \\
\hline $\begin{array}{c}\text { NanoWeb- } \\
\text { RVC }\end{array}$ & $2.70 \pm 0.08$ & $\begin{array}{c}0.210 \pm \\
0.006\end{array}$ & $1.3 \pm 0.2$ & $0.10 \pm 0.01$ \\
\hline
\end{tabular}

Comparatively, Zhang et al. ${ }^{33}$ obtained a maximum rate of about $0.01 \mathrm{mM} \mathrm{cm}^{-2}$ day $^{-1}$ of acetate with their CNT-cotton and CNT-polyester materials, versus $1.3 \mathrm{mM} \mathrm{cm}^{-2} \mathrm{day}^{-1}$ on NanoWeb-RVC reported in this study. Min et al. ${ }^{45}$ reported $0.387 \mathrm{mM} \mathrm{cm}^{-2}$ day $^{-1}$ (vs. projected area) of acetate produced by a mixed culture at $-0.9 \mathrm{~V}$ on carbon felt, under experimental conditions very similar to ours. Marshall et al. ${ }^{9}$, who also used mixed microbial cultures, reported a high acetate production rate of $4 \mathrm{mM}$ day $^{-1}$ with graphite granules as cathode material. However, the available cathode surface area was not mentioned and a comparison can therefore not be made. Hence, to the best of our knowledge, we report here the highest acetate production rate obtained in a biocathode from $\mathrm{CO}_{2}$ reduction, a production increase of more than an order of magnitude compared to previously published data $^{33,45}$.
Concomitant to acetate production, hydrogen did not accumulate in the headspaces of the reactors, unlike what was reported by Marshall et al. ${ }^{9}$ Even though hydrogen was not detected, this does not exclude a possible mechanism of electron transfer from the cathode towards acetogens, through either abiotic or bio-catalysed hydrogen production. Indeed, it could be envisioned that hydrogen is produced and consumed by acetogens before detection could be possible. Therefore, it is possible that electrons are either being directly delivered from the cathode to the acetate-producing microorganisms, or through mediated electron transfer. Electron transfer via biotically generated hydrogen was hypothesized in a previous study for microbial electrosynthesis of methane and acetate ${ }^{9}$, and it was recently shown that $\mathrm{H}_{2}$-producing microorganisms could indeed sustain growth for long-term hydrogen production on biocathodes ${ }^{51}$. However, a detailed mechanistic study was beyond the focus of this work and further research needs to be undertaken to elucidate the extracellular electron transfer mechanisms occurring in such systems.

\section{Biofilm development}

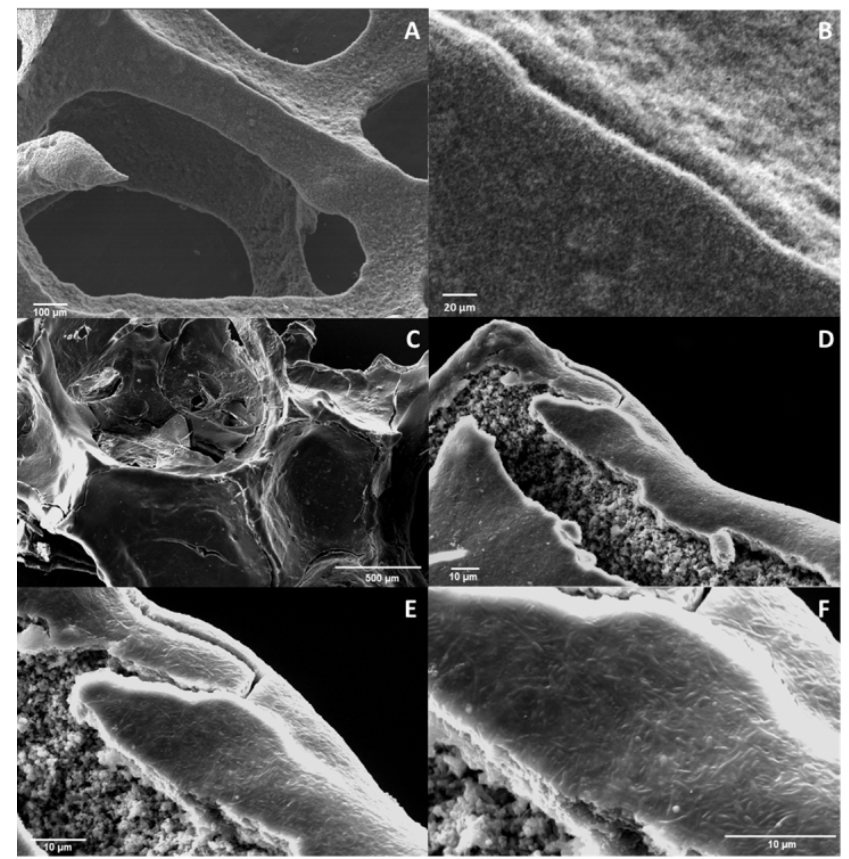

Fig. 3 Scanning Electron Micrographs (SEM) images at different magnification of (A), (B) bare NanoWeb-RVC; (C) to (F) a putative electroactive biofilm grown on the NanoWeb-RVC.

Images of both NanoWeb-RVC before and 140 days after inoculation are shown in Fig. 3. The CNT NanoWeb was successfully developed and appears as a fine roughness on the surface (Fig. 3A and B), in contrast to the flat and smooth unmodified RVC (Fig. 4A). ${ }^{28}$ The CNT NanoWeb was previously characterised and showed intertwined fine carbon nanotubes with an average diameter of about $60 \mathrm{~nm}$ and pore size within their web of $100 \mathrm{~nm}$ or smaller. ${ }^{28,} 44$ The RVC original macrostructure was not altered in this process, which is critical for biofilm development and mass transfer considerations. 
At the end of the chronoamperometry experiments, the threedimensional electrodes were taken out of the reactors, cut into pieces and prepared for SEM observation. Fig. 3C-F show SEM micrographs at different magnifications depicting a uniform and fairly thick and continuous structure which is attributed to a biofilm formed on the NanoWeb-RVC electrode surface during the chronoamperometry experiment. A layer with very high density of rod shape microorganisms about 1-2 $\mu \mathrm{m}$ long entangled in an extracellular polymer-like substance can be observed.

In Fig. 3D and Fig. 3E, the biofilm appears damaged, most probably due to the fixation and drying processes. These images allow us to estimate the biofilm thickness to be about 5 $\pm 2 \mu \mathrm{m}$ in dry state. To date, very limited information on cathodic biofilm thickness has been reported in the literature. The thickness observed in this study represents a rather thin biofilm obtained after 140 days of experiment, compared to observed thicknesses of anodic biofilms of up to $100 \mu \mathrm{m} .^{52}$

Fig. 4A shows an SEM image of unmodified RVC before reactor inoculation. Fig. $4 \mathrm{~B}$ and $\mathrm{C}$ show images of unmodified RVC that remained for 140 days in the bioelectrochemical reactor in the presence of inoculum and under the same conditions as NanoWeb-RVC and carbon plates. The surface of the unmodified-RVC appears to be largely unchanged over the 140 days of operation, with no biofilm development or any other deposits apparent on the surface.

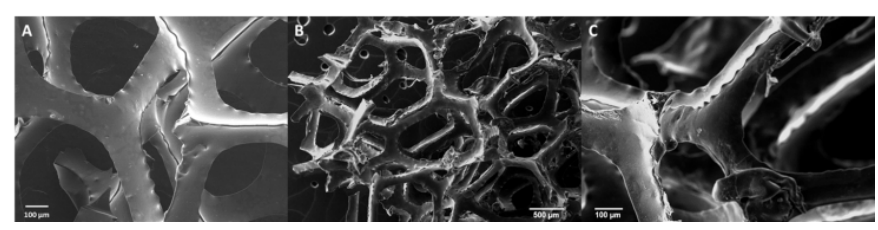

Fig. 4 SEM images of unmodified-RVC before (A) and 140 days after inoculation (B-C) at different magnifications.

On the other hand, the optical density development at $660 \mathrm{~nm}$ of the cathodic medium of the unmodified-RVC reactor (Fig. 5) suggests that microorganisms were present in suspension and their concentration slightly increased up to day 70 and stabilized thereafter. This observation is consistent with the fact that some carbon dioxide was consumed in this reactor (Fig. 2) even though no acetate was produced, as previously shown. We can notice a similar trend in the NanoWeb-RVC reactor, with the optical density increasing until day 90 then flattening out for some days before decreasing.

The absence of biofilm and acetate production on unmodified RVC, plus the observation of similar amounts of planktonic cells in the catholyte of the NanoWeb-RVC reactor, strongly suggests that the biofilm plays a pivotal role in the high current consumption and electrosynthesis performance of the NanoWeb-RVC. Furthermore, the decrease in optical density after day 100 coincides with an actual enhancement of the carbon dioxide consumption and acetate production rates on NanoWeb-RVC. This decrease further shows that planktonic cells are unlikely to play an important role in this process and that the biofilm is primarily responsible for the $\mathrm{CO}_{2}$ to acetate conversion. SEM observations strongly suggest that the much larger electron consumption rate reached on NanoWeb-RVC versus unmodified-RVC (10 times lower and constant current) throughout the experiment can be attributed to the development of a uniform biofilm covering the three-dimensional structure. However, further research will be needed to assess the relative importance of both biofilm and microorganisms in suspension in microbial electrosynthesis performance.

Microbial electrosynthesis is most probably not possible on unmodified vitreous carbon as shown by our results.

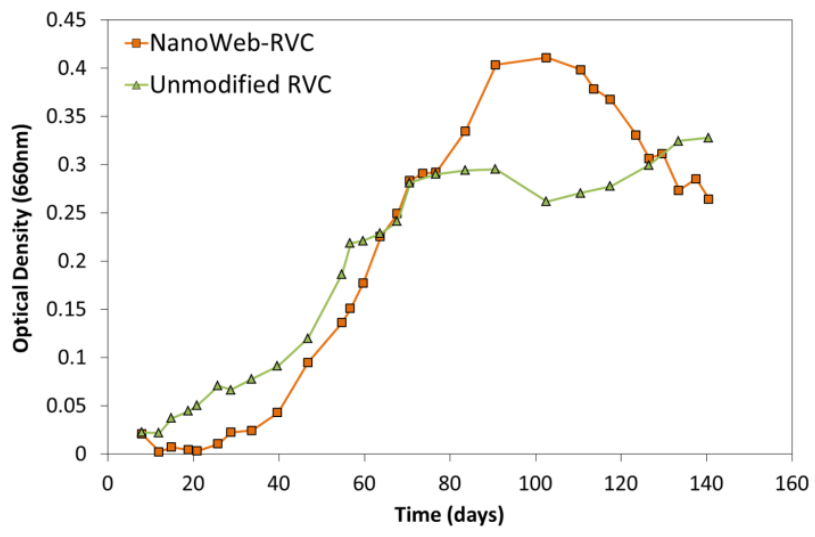

Fig. 5 Optical density development over time in the cathodic media in both the NanoWeb-RVC and the unmodified RVC reactors.

Nevertheless, we did want to compare the bioelectrosynthesis performance of the porous electrodes to flat electrodes, hence the choice of commercially available carbon plates as control instead of flat vitreous carbon.

All these observations indicate that the NanoWeb CNTs are highly biocompatible and support a highly enhanced bacterial attachment and biofilm development on top of the nano-porous structure. Moreover, the very high current density obtained suggests that the microorganism-electrode interaction is improved compared to the rough carbon plates, allowing for a maximisation of the electron transfer rate. The nanometre scale roughness of the NanoWeb-RVC electrodes can be seen in Fig. 3A and B. It should be stressed that the maximum size of the pores created by the NanoWeb are 100 nanometre, i.e. are at least one order of magnitude smaller than typical bacterial sizes (about $1 \mu \mathrm{m}$ length, see Fig. 3F). Therefore, the NanoWeb does not increase the available surface area for bacteria immobilisation but primarily enhances the interaction between the electrode surface and the microbial cells ${ }^{28}$. We hypothesize that the somewhat flexible NanoWeb surface structure ${ }^{44}$ offers multiple anchoring points for bacterial adhesion, as opposed to the unmodified, flat and rigid RVC surface or rough carbon plates. Additionally, the fact that the CNTs are chemically 'grown' on the RVC surface likely creates a high density of active electron transfer locations, which can then directly interact with the microbial cells growing on top. Irrespective of which electron transfer mechanism these bacteria use (direct membrane-bound proteins, bacterial nanowires or soluble extracellular redox mediators), the NanoWeb surface seems to 
stimulate and support effective, likely multipoint electron transfer processes between each attached bacteria and the electrode surface. The combination of this effective nano-scale surface modification with the large specific surface area and high porosity of the RVC macrostructure is believed to be largely responsible for such strong enhancement of the current density, $\mathrm{CO}_{2}$ consumption and acetate production rates achieved in this study with the novel NanoWeb-RVC electrode material.

\section{Conclusions}

We have demonstrated in this study that the performance of microbial electrosynthesis of organics from carbon dioxide reduction can be significantly improved using a novel microbial biocathode, NanoWeb-RVC. To the best of our knowledge, results presented here correspond to the highest current density (3.7 $\mathrm{mA} \mathrm{cm} \mathrm{cm}^{-2}$ normalized by projected surface area) and bioproduction rate $\left(1.3 \mathrm{mM} \mathrm{cm}{ }^{-2}\right.$ day $^{-1}$ of acetate) reached to date on biocathodes for bio-reduction of carbon dioxide.

The electron transfer rate between electrode-microorganisms (1.65-fold) and the acetate bioproduction rate (2.6-fold) were substantially enhanced on NanoWeb-RVC (normalised by total surface area) compared to rough graphite plate electrodes. From our understanding, this is the first study showing higher performance normalized to total surface area reached by a porous three-dimensional electrode versus a rough graphite electrode (we stress once more the difference in normalizing vs. total surface area or normalizing vs. projected surface area). The results show that the NanoWeb-RVC has a very high intrinsic performance as a biocathode material for MES. This also suggests that mass transfer through the macropores, and to and from the biofilm, was very effective. Multiwalled-CNT directly grown on a highly conductive three-dimensional substrate such as RVC enables such MES performance improvements. Other studies that tested electrodes produced by dipping a non-conductive substrate in a CNT ink did not show such improvements compared either to their control or to the results presented here. ${ }^{33}$ Moreover, we have shown that on unmodified RVC (without CNT) microbes did not attach to the surface and bio-reduction of $\mathrm{CO}_{2}$ to acetate did not occur. Therefore the CNT nanostructure increases the electrode's biocompatibility and actually makes it possible for a continuous, electroactive biofilm to be formed, with increased microbial extracellular electron transfer. Additionally, NanoWeb-RVC electrodes offer a high available surface area for biofilm development per volume, which is important from a reactor design and engineering perspective.

These results bring microbial electrosynthesis one step closer to practical applications. NanoWeb-RVC seems a very promising electrode material for practical MES processes and specifically for reactor scale-up. Future research should focus on elucidating what actually limits the maximally achievable performance by carbon nanotube modified scaffolds. Moreover, mechanistic studies aiming at understanding the pathways by which electrons are transferred from cathodes to microorganisms are still lacking. This would be useful information for the optimization of the operational conditions (e.g. applied potential) and reactor design for microbial electrosynthesis.

\section{Experimental}

\section{Preparation of NanoWeb-RVC}

Synthesis of RVC-NanoWeb has previously been reported. ${ }^{28,44}$ Briefly, NanoWeb-RVC was grown using chemical vapour deposition (CVD) onto reticulated vitreous carbon (45 ppi, Duocel, ERG Materials and Aerospace Corporation), which was first coated with a thin layer of catalyst solution consisting of $10 \%(\mathrm{w} / \mathrm{w})$ iron(III) para-toluenesulfonate (Baytron) in ethanol. Substrates were briefly immersed in the $10 \%(\mathrm{w} / \mathrm{w})$ catalyst solution before being removed, shaken to remove excess solution, and then allowed to dry until all the excess oxidant had drained. The solvent was then removed using a $100{ }^{\circ} \mathrm{C}$ oven. CVD growth of the NanoWeb material was achieved using a Thermal CVD system (Atomate). Initially the system was flushed with Ar (200 mL min ${ }^{-1}$ ) for 30 minutes, after which the furnace temperature was increased to $600{ }^{\circ} \mathrm{C}$ whilst a mixture of $\operatorname{Ar}\left(150 \mathrm{~mL} \mathrm{~min}^{-1}\right)$ and $\mathrm{H}_{2}\left(20 \mathrm{~mL} \mathrm{~min}^{-1}\right)$ was passed through the furnace. The furnace temperature was then maintained at $600{ }^{\circ} \mathrm{C}$ for 10 minutes, resulting in reduction of the iron(III) catalyst to iron nanoparticles. Growth of the NanoWeb was then initiated by ramping the temperature up to $800{ }^{\circ} \mathrm{C}$ at which point acetylene gas $\left(10 \mathrm{~mL} \mathrm{~min}^{-1}\right)$ was passed through the furnace whilst maintaining a constant flow of $\mathrm{Ar}$ (200 $\mathrm{mL} \mathrm{min}^{-1}$ ) and $\mathrm{H}_{2}\left(3 \mathrm{~mL} \mathrm{~min}^{-1}\right)$. Synthesis of the NanoWeb was complete after 30 minutes, at which point the furnace, acetylene and $\mathrm{H}_{2}$ were turned off, and the system flushed continuously with $\operatorname{Ar}\left(150 \mathrm{~mL} \mathrm{~min}^{-1}\right)$ until the temperature was less than $100{ }^{\circ} \mathrm{C}$.

Electrochemical characterisation with a classical reversible redox couple, ferrycianide $10 \mathrm{mM}$, of both NanoWeb-RVC and Unmodified RVC was carried out in a standard three-electrode cell with a $0.1 \mathrm{M} \mathrm{NaNO}_{3}$ solution containing at a scan rate of $5 \mathrm{mV} \mathrm{s}^{-1}$.

\section{Electrode preparation}

NanoWeb-RVC, unmodified RVC and graphite plates were pierced with a $0.5 \mathrm{~mm}$ thick $\mathrm{Ti}$ wire that acted as a current collector. The electrical connection was reinforced by means of conductive carbon paint that was let to dry for 1 day.

Graphite plates (50 mm x 19.3 mm x 4 mm; Morgan AM\&T, Sydney, NSW, Australia) were used as cathode electrodes. They were specifically modified by making $1.4 \mathrm{~mm}$ deep grooves on each side, in order to obtain 8 easily detachable 8.5 $\mathrm{mm}^{2}$ squares per electrode, for further analysis. The total surface area of the modified plates was calculated to be $29 \mathrm{~cm}^{2}$. The graphite electrodes were washed with $1 \mathrm{M}$ hydrochloric acid, $1 \mathrm{M}$ sodium hydroxide (24 hours in each) to remove organic and metal contamination, and rinsed in deionized water after each step. 
Unmodified RVC electrodes were cut into blocks of (1.6 x 1.25) $\mathrm{cm}$, and they were $0.46 \mathrm{~cm}$ thick. NanoWeb-RVC electrodes were cut in blocks of $(0.6 \times 0.6) \mathrm{cm}$, and they were $0.44 \mathrm{~cm}$ thick. The projected surface area of the electrodes refers to the footprint of the base of the electrode. ${ }^{28}$ The projected surface area determines the size of a bioelectrochemical reactor for engineering applications. Also, since the carbon paint blocked a few of the pores, the surface area and the volume values used for normalization do not consider this area/volume. According to our definition of total surface area at the beginning of the Results and Discussion Section, the total surface areas are 24.9 and $4.1 \mathrm{~cm}^{2}$ for the unmodified RVC and NanoWeb-RVC electrodes, respectively. Therefore, in our experiments the projected surface area of the unmodified RVC electrodes was $1.85 \mathrm{~cm}^{2}$ while the NanoWebRVC electrodes bear a projected surface area of $0.32 \mathrm{~cm}^{2}$.

All electrodes were pre-treated in a $\mathrm{N}_{2}$ plasma for 20 minutes before being introduced in the reactors in order to remove surface contamination and render the surface hydrophilic. ${ }^{18}$

\section{Source of microorganisms}

A mixed microbial consortium from natural environments (stormwater pond sediments, located on the University of Queensland, St Lucia campus, Brisbane, Australia) and engineered anaerobic systems (from the Luggage Point Waste Water Treatment Plant anaerobic digester, Brisbane, Australia) were combined and added to a final concentration of 60 $\mathrm{mg}_{\mathrm{COD}} \cdot \mathrm{L}^{-1}$ in the reactors on the same day.

\section{Electrochemical experiments}

Each cathode material was tested under strict anaerobic conditions, at $35{ }^{\circ} \mathrm{C}$, in a three-electrode/two-chamber system (see Fig S1 in Supporting Information). All experiments were carried out under dark conditions to avoid phototrophic activity. Glass bottles were specifically designed, with a cathode chamber volume of approximately $300 \mathrm{~mL}$. A $1 \mathrm{~cm}$ diameter, $15 \mathrm{~cm}$ long glass tube was inserted through the bottle top and served as the anode chamber, with a platinum wire as counter electrode (purity 99.95\%, $0.50 \mathrm{~mm}$ diameter x $50 \mathrm{~mm}$ long, Advent Research Materials, Oxford, England). The chambers are separated by a cation exchange membrane (CEM) (Ultrex CM17000, Membranes International, NJ, USA). Two ports were placed in order to take samples from both the liquid phase and the headspace. A custom-made $\mathrm{KCl}$ saturated $\mathrm{Ag} / \mathrm{AgCl}$ reference electrode was inserted into the bottle in proximity of the cathode. All potentials are reported here versus Standard Hydrogen Electrode (SHE). The BESs were operated in fedbatch mode. A multi-channel potentiostat ( $\mathrm{CH}$ Instruments, Austin, TX, USA) was used for all experiments. During all experiments, the cathode was poised chronoamperometrically at $-0.85 \mathrm{~V}$ for 140 days. The total charge (Coulomb) consumed was calculated by integrating the area under the current versus time curve (i-t curve). Two NanoWeb-RVC electrodes were immersed in one reactor as duplicates for current consumption. Similarly, two unmodified RVC electrodes were introduced in another reactor. A third reactor with two graphite plate electrodes was used as control. A gas bag (Flexfoil plus, AirMet Scientific Pty Ltd, QLD, Australia), specified for collection of $\mathrm{CO}_{2}, \mathrm{H}_{2}$ and $\mathrm{CH}_{4}$, was connected to the reactors to measure gas composition and production rate and avoid pressure increase within the cathode chamber.

The cathode chamber was filled with $250 \mathrm{~mL}$ (acetic acid production rates and $\mathrm{CO}_{2}$ consumption rates are calculated using this value) of a medium containing: $0.2 \mathrm{~g} \mathrm{~L}^{-1} \mathrm{NH}_{4} \mathrm{CL}$, $0.04 \mathrm{~g} \mathrm{~L}^{-1} \mathrm{MgCl}_{2} .6 \mathrm{H}_{2} \mathrm{O}, 0.015 \mathrm{~g} \mathrm{~L}^{-1} \mathrm{CaCl}_{2}, 6 \mathrm{~g} \mathrm{~L}^{-1} \mathrm{Na}_{2} \mathrm{HPO}_{4}, 3$ $\mathrm{g} \mathrm{L}^{-1} \mathrm{KH}_{2} \mathrm{PO}_{4}$ and $1 \mathrm{~mL} \mathrm{~L}^{-1}$ of a trace element solution as described in Jourdin et al. ${ }^{51}$. Final concentration of 0.5 to $2 \mathrm{~g} \mathrm{~L}^{-}$

${ }^{1} \mathrm{NaHCO}_{3}$ was added periodically as sole carbon source. To suppress methanogenic activity, $15 \mathrm{mM}$ 2-bromoethanesulfonic acid was added initially. The medium was prepared under anaerobic conditions (flushed with $100 \% \mathrm{~N}_{2}$ ) and introduced into the cathode compartment inside an anaerobic chamber. During the experiment, the catholyte medium $\mathrm{pH}$ was regularly adjusted to 7 by dosing $1 \mathrm{M} \mathrm{HCl}$ as needed. The anolyte contained $44 \mathrm{mg} \mathrm{L}^{-1} \mathrm{Na}_{2} \mathrm{HPO}_{4}$ and $25 \mathrm{mg} \mathrm{L}^{-1} \mathrm{KH}_{2} \mathrm{PO}_{4}$.

\section{Analytical methods}

Liquid samples (11.5 mL) were taken out of the cathode compartment through a rubber stopper using a $15 \mathrm{~mL}$ syringe equipped with a sterile needle, and were immediately filtered through a $0.22 \mu \mathrm{m}$ filter.

Volatile fatty acids were measured using a gas chromatography (GC) apparatus (Agilent Technologies 7890A GC System) equipped with a flame ionisation detector (FID; $10 \mathrm{~mL} \mathrm{~min}{ }^{-1}$ $\mathrm{N}_{2} ; 250^{\circ} \mathrm{C}$ ) and a polar capillary column (DB-FFAP $15 \mathrm{~m} \mathrm{x}$ $0.53 \mathrm{~mm} \times 1.0 \mu \mathrm{m})$. High purity helium flowing with an initial flow of $12.5 \mathrm{~mL} \mathrm{~min}{ }^{-1}$ was used as carrier gas. $0.9 \mathrm{~mL}$ sample was added to $0.1 \mathrm{~mL}$ of $10 \%$ formic acid solution and $0.5 \mu \mathrm{L}$ of this mixture were injected in pulsed splitless at $220^{\circ} \mathrm{C}$.

Analytik Jena multi N/C 2100S Total Organic Carbon Analyser was used for the total inorganic carbon (TIC) analysis and followed the bicarbonate consumption. $250 \mu \mathrm{L}$ samples were injected into a 2.6 $\mathrm{M}$ phosphoric acid solution and the resulting carbon dioxide was stripped of the solution and into the near infrared detector with a stream of oxygen.

$5 \mathrm{~mL}$ gas samples were taken from the reactor headspace using a gas tight syringe. Beforehand, the gas bag was disconnected from the reactor and the volume of gas produced between two sampling steps was assessed and a $\mathrm{N}_{2}$-full gas bag was connected to the reactor. Methane, hydrogen and carbon dioxide gases were measured on a gas chromatographyThermal Conductivity Detection (GC-TCD). The system was a Perkin Elmer auto system GC-TCD with a $2.44 \mathrm{~m}$ stainless steel column packed with Haysep (80/100 mesh). The GC was fitted with a GC Plus Data station, Model 1022 (Perkin Elmer, Waltham, MA, USA). High purity nitrogen (99.99\%) was used as carrier gas at a flow rate of $24.3 \mathrm{~mL} / \mathrm{min}$ and a pressure of $380 \mathrm{kPa}$. The injection port, oven and detector were operated at $75^{\circ} \mathrm{C}, 40^{\circ} \mathrm{C}$ and $100{ }^{\circ} \mathrm{C}$, respectively.

Optical density of non-filtered samples was assessed using a UV-visible spectrophotometer (Varian, Cary 50 Conc UVVisible Spectrophotometer, California, USA) at $660 \mathrm{~nm}$. 


\section{Scanning electron microscopy (SEM)}

Scanning electron microscope images of the bare electrodes were obtained using a JEOL JSM 7500FA cold-field-gun field emission microscope (SEM images shown in Fig. 3A and B and 4A).

After biofilm development, electrode samples from the cathode were fixed in 5\% glutaraldehyde for $2 \mathrm{~h}$. The samples then underwent a MilliQ ${ }^{\circledR}$ water postfix wash. Dehydrated $(<24$ h in a high vacuum desiccator) and subsequently carbon coated (QT150TS Turbo-pumped coater, Argon purged) samples were imaged in secondary electron mode employing a XL30 Philips conventional (LaB6 source electron gun) Scanning Electron Microscope. Samples were imaged at $15 \mathrm{kV}$ acceleration, 10-15 mm working distance and 5.1 spot size.

\section{Acknowledgements}

VF acknowledges a UQ Postdoctoral Fellowship. This work was supported by the Australian Research Council Grant DP110100539. JC and GGW would like to thank the ACES and ANFF for continuous support. In addition, GGW acknowledges the support of the ARC in the form of an Australian Laureate Fellowship. The authors acknowledge the facilities and the scientific and technical assistance of the Australian Microscopy \& Microanalysis Research Facility at the Centre for Microscopy and Microanalysis (The University of Queensland).

\section{Notes}

${ }^{a}$ The University of Queensland, Advanced Water Management Centre, Level 4, Gehrmann Building (60), Brisbane, QLD 4072, Australia

${ }^{b}$ Centre for Microbial Electrosynthesis, Gehrmann Building, The University of Queensland, Brisbane, Queensland 4072, Australia.

${ }^{c}$ ARC Centre of Excellence for Electromaterials Science, Intelligent Polymer Research Institute, AIIM Facility, Innovation Campus, University of Wollongong, NSW, 2522, Australia

¥ Present address: Department of Analytical Chemistry, Ghent University, Krijgslaan 281 S12, Ghent 9000 BELGIUM

*Corresponding authors: Victoria Flexer (victoria.flexer@ugent.be) and Ludovic Jourdin (l.jourdin@awmc.uq.edu.au)

$\dagger$ Electronic Supplementary Information (ESI) available. See DOI: 10.1039/b000000x/

\section{References}

1. D. R. Lovley and K. P. Nevin, Current Opinion in Biotechnology, 2011, 22, 441-448.

2. K. Rabaey and R. A. Rozendal, Nat Rev Micro, 2010, 8, 706-716.

3. D. R. Lovley and K. P. Nevin, Current Opinion in Biotechnology, 2013, 24, 385-390.

4. K. Rabaey, P. Girguis and L. K. Nielsen, Current Opinion in Biotechnology, 2011, 22, 371-377.
5. N. S. Lewis and D. G. Nocera, Proceedings of the National Academy of Sciences of the United States of America, 2006, 103, 15729-15735.

6. J. Desloover, J. B. A. Arends, T. Hennebel and K. Rabaey, Biochemical Society Transactions, 2012, 40, 1233-1238.

7. K. P. Nevin, S. A. Hensley, A. E. Franks, Z. M. Summers, J. Ou, T. L. Woodard, O. L. Snoeyenbos-West and D. R. Lovley, Applied and Environmental Microbiology, 2011, 77, 2882-2886.

8. K. P. Nevin, T. L. Woodard, A. E. Franks, Z. M. Summers and D. R. Lovley, mBio, 2010, 1.

9. C. W. Marshall, D. E. Ross, E. B. Fichot, R. S. Norman and H. D. May, Applied and Environmental Microbiology, 2012, 78, 84128420.

$10 . \quad$ C. W. Marshall, D. E. Ross, E. B. Fichot, R. S. Norman and H. D. May, Environmental Science and Technology, 2013, 47, 60236029.

11. K.-J. Chae, M.-J. Choi, J.-W. Lee, K.-Y. Kim and I. S. Kim, Bioresource Technology, 2009, 100, 3518-3525.

12. M. Köpke, C. Held, S. Hujer, H. Liesegang, A. Wiezer, A. Wollherr, A. Ehrenreich, W. Liebl, G. Gottschalk and P. Dürre, Proceedings of the National Academy of Sciences of the United States of America, 2010, 107, 13087-13092.

13. C. Leang, T. Ueki, K. P. Nevin and D. R. Lovley, Applied and Environmental Microbiology, 2013, 79, 1102-1109.

14. S. Cheng and B. E. Logan, Electrochemistry Communications, 2007, 9, 492-496.

15. S. R. Higgins, D. Foerster, A. Cheung, C. Lau, O. Bretschger, S. D. Minteer, K. Nealson, P. Atanassov and M. J. Cooney, Enzyme and Microbial Technology, 2011, 48, 458-465.

16. X.-W. Liu, X.-F. Sun, Y.-X. Huang, G.-P. Sheng, S.-G. Wang and H.-Q. Yu, Energy \& Environmental Science, 2011, 4, 1422-1427.

17. Y. Qiao, C. M. Li, S.-J. Bao and Q.-L. Bao, Journal of Power Sources, 2007, 170, 79-84.

18. V. Flexer, M. Marque, B. C. Donose, B. Virdis and J. Keller, Electrochimica Acta, 2013, 108, 566-574.

19. K. Guo, X. Chen, S. Freguia and B. C. Donose, Biosensors and Bioelectronics, 2013, 47, 184-189.

$20 . \quad$ D. H. Park and J. G. Zeikus, Biotechnology and Bioengineering, 2003, 81, 348-355.

21. A. L. Popov, J. R. Kim, R. M. Dinsdale, S. R. Esteves, A. J. Guwy and G. C. Premier, Biotechnology and Bioprocess Engineering, 2012, 17, 361-370.

22. K. Wang, Y. Liu and S. Chen, Journal of Power Sources, 2011, 196, 164-168.

23. Y. Fan, S. Xu, R. Schaller, J. Jiao, F. Chaplen and H. Liu, Biosensors and Bioelectronics, 2011, 26, 1908-1912.

$24 . \quad$ B. K. Jena, S. Ghosh, R. Bera, R. S. Dey, A. K. Das and C. Retna Raj, Recent Patents on Nanotechnology, 2010, 4, 41-52.

25. J. Wei, P. Liang and X. Huang, Bioresource Technology, 2011, 102, 9335-9344.

26. C. M. Welch and R. G. Compton, Analytical and Bioanalytical Chemistry, 2006, 384, 601-619.

27. S. Chen, G. He, Q. Liu, F. Harnisch, Y. Zhou, Y. Chen, M. Hanif, S. Wang, X. Peng, H. Hou and U. Schroder, Energy \& Environmental Science, 2012, 5, 9769-9772.

$28 . \quad$ V. Flexer, J. Chen, B. C. Donose, P. Sherrell, G. G. Wallace and J. Keller, Energy and Environmental Science, 2013, 6, 1291-1298.

$29 . \quad$ Z. He, S. D. Minteer and L. T. Angenent, Environmental Science \& Technology, 2005, 39, 5262-5267.

$30 . \quad$ B. R. Ringeisen, E. Henderson, P. K. Wu, J. Pietron, R. Ray, B. Little, J. C. Biffinger and J. M. Jones-Meehan, Environmental Science \& Technology, 2006, 40, 2629-2634.

31. M. Zhou, M. Chi, J. Luo, H. He and T. Jin, Journal of Power Sources, 2011, 196, 4427-4435.

32. K. Guo, S. Freguia, P. G. Dennis, X. Chen, B. C. Donose, J. Keller, J. J. Gooding and K. Rabaey, Environmental Science \& Technology, 2013, 47, 7563-7570.

33. T. Zhang, H. Nie, T. S. Bain, H. Lu, M. Cui, O. L. SnoeyenbosWest, A. E. Franks, K. P. Nevin, T. P. Russell and D. R. Lovley, Energy \& Environmental Science, 2013, 6, 217-224.

34. H. Nie, T. Zhang, M. Cui, H. Lu, D. R. Lovley and T. P. Russell, Physical Chemistry Chemical Physics, 2013, 15, 14290-14294. 
35. A. E. Franks, K. P. Nevin, H. Jia, M. Izallalen, T. L. Woodard and D. R. Lovley, Energy \& Environmental Science, 2009, 2, 113119.

36. U. Schroder, Physical Chemistry Chemical Physics, 2007, 9, 2619-2629.

37. J. M. Friedrich, C. Ponce-de-León, G. W. Reade and F. C. Walsh, Journal of Electroanalytical Chemistry, 2004, 561, 203-217.

$38 . \quad$ A. Walcarius, S. D. Minteer, J. Wang, Y. Lin and A. Merkoci, Journal of Materials Chemistry B, 2013, 1, 4878-4908.

39. M. C. Gutierrez, Z. Y. Garcia-Carvajal, M. J. Hortiguela, L. Yuste, F. Rojo, M. L. Ferrer and F. del Monte, Journal of Materials Chemistry, 2007, 17, 2992-2995.

40. K. Katuri, M. L. Ferrer, M. C. Gutierrez, R. Jimenez, F. del Monte and D. Leech, Energy \& Environmental Science, 2011, 4, 42014210.

41. J. E. Mink, J. P. Rojas, B. E. Logan and M. M. Hussain, Nano Letters, 2012, 12, 791-795.

42. X. Xie, M. Pasta, L. Hu, Y. Yang, J. McDonough, J. Cha, C. S. Criddle and Y. Cui, Energy \& Environmental Science, 2011, 4, 1293-1297.

43. X. Xie, M. Ye, L. Hu, N. Liu, J. R. McDonough, W. Chen, H. N. Alshareef, C. S. Criddle and Y. Cui, Energy \& Environmental Science, 2012, 5, 5265-5270.

44. J. Chen, A. I. Minett, Y. Liu, C. Lynam, P. Sherrell, C. Wang and G. G. Wallace, Advanced Materials, 2008, 20, 566-570.

45. S. Min, Y. Jiang and D. Li, Journal of Microbiology and Biotechnology, 2013, 23, 1140-1146.

46. C. Dumas, R. Basseguy and A. Bergel, Electrochimica Acta, 2008, 53, 2494-2500

47. A. W. Jeremiasse, H. V. M. Hamelers and C. J. N. Buisman, Bioelectrochemistry, 2010, 78, 39-43.

$48 . \quad$ B. E. Logan, D. Call, S. Cheng, H. V. M. Hamelers, T. H. J. A. Sleutels, A. W. Jeremiasse and R. A. Rozendal, Environmental Science \& Technology, 2008, 42, 8630-8640.

$49 . \quad$ R. A. Rozendal, H. V. M. Hamelers, G. J. W. Euverink, S. J. Metz and C. J. N. Buisman, International Journal of Hydrogen Energy, 2006, 31, 1632-1640.

50. R. A. Rozendal, A. W. Jeremiasse, H. V. M. Hamelers and C. J. N. Buisman, Environmental Science and Technology, 2008, 42, 629-634.

51. L. Jourdin, S. Freguia, B. C. Donose and J. Keller, Submitted for publication, 2014.

52. K. P. Nevin, B. C. Kim, R. H. Glaven, J. P. Johnson, T. L. Woodward, B. A. Methé, R. J. Didonato Jr, S. F. Covalla, A. E. Franks, A. Liu and D. R. Lovley, PLoS ONE, 2009, 4. 